\title{
Clinical determinants of placental morphometry and birth weight
}

\author{
Rupa LB ${ }^{1}$, VS Shirol ${ }^{2}$, Anita $\mathrm{MG}^{3}$, NK Tyagi ${ }^{4}$ \\ 1. Anatomy department, Jawaharlal Nehru Medical College/ KLE University, India. \\ 2. Anatomy department, Jawaharlal Nehru Medical College/ KLE University, India. \\ 3. Obstetrics and Gynaecology department, Jawaharlal Nehru Medical College/ KLE University, India. \\ 4. Epidemiology and Biostatistics department/KLE University, India.
}

\begin{abstract}
Placental morphometry and fetal growth trajectory are directly related to maternal health profile. Inutero environment influences the placental morphometry and the foetal growth, any imbalance in the equilibrium of this triad leads to adverse pregnancy outcome and long term risk of chronic diseases in the newborn.

Present study was conducted on 164 consecutive singleton deliveries from a teaching hospital of North Karnataka, India from Sept 2012 to Jan 2013. The study was designed to explore the influence of the adverse pregnancy symptoms and conditions on the birth weight and placental morphometry.

The Mean and standard deviation (SD) of placental morphometry; weight, volume, surface area and thickness were $414.7 \pm 110.5 \mathrm{gm}, 363.1 \pm 113.2 \mathrm{ml}, 223.7 \pm 54.7 \mathrm{sqcm}$, and $2.1 \pm 0.5 \mathrm{~cm}$ respectively with birth weight mean $\pm S D 2536.1 \pm 675.5 \mathrm{gm}$.

Mild vomiting exhibited increase in birth weight and placental morphometry. Rise in either systolic or diastolic blood pressure exhibited positive and significant relationship with; placental weight, thickness ( $p<0.01)$ volume, and birth weight $(p<0.05)$. Mild oedema, severe anaemia and protienuria were associated with decreased birth weight and placental morphometry, but not significantly.

The results of the present study will help clinicians to correlate the adverse pregnancy symptoms and conditions with growth of placenta and fetus. Severe adverse pregnancy symptoms and conditions lead to abnormal placental morphometry and birth weight reflecting the worsening of pregnancy outcome.

Key words: Placental weight, placental volume, placental surface area, placental thickness, vomiting, blood pressure, pallor
\end{abstract}

\section{Introduction}

During pregnancy many problems occur from different sources; chromosome and genetic disorders of the foetus, maternal illness or behaviour, environmental factors, and the most important placental abnormalities leading to foetal abnormalities and death. Placenta is a multifunctional, transient, vital organ of pregnancy which serves as a mirror of perinatal period with pleiotropic roles to support the foetal development. Placenta helps in the maintenance of pregnancy and nourishment of the developing fetus [1]. Earlier, it was believed that high placental weight was associated with a poor perinatal outcome, a low APGAR score, respiratory distress and perinatal death, whereas a low placental weight was associated with medical complications in the mother [2] but recent studies indicate that the altered growth of the placenta is a predictor of adult onset of diseases like cardiovascular disease, hypertension and diabetes. A large placenta and a low birth weight were reported as strong independent risk factors of cardiovascular diseases [3].

Placental weight is a gross summary, unable to explain the biological and mechanical information. A multi-dimensional measure of placental growth provides more knowledge into the underlying mechanism of fetal adaptation and the gestational intervals at which the changes occur in the placenta [4].

Many studies have been done to assess effect of gestation induced maternal diseases with placenta and birth weight. There is literature paucity regarding the studies to assess the influence of adverse pregnancy symptoms and conditions alone on the placental morphometry (weight, volume, surface area and thickness) and birth weight. Therefore present study attempts to address the lacuna and helps to evaluate the effect of adverse pregnancy symptoms like vomiting, oedema, blood pressure, pallor, antepartum haemorrhage, premature rupture of membrane, haemoglobin, urine test on the placental morphometry and birth weight.

\section{Materials and method}

Present study was carried out in Dr Prabhakar Kore Hospital and Medical Research Centre, Belgaum (North Karnataka, India) from September 2012 to January 2013. Study was conducted on 164 placentae and neonates from Obstetrics and Gynecology unit. The study was approved by the Institutional Ethical Clearance Committee. Informed and written consent was obtained from mothers. Study included the placentae from consecutive singleton normal deliveries and cesarean sections. Mothers of the age group18-40 years and 
gestational age ranging from 28-41 weeks were included. The data about demographic and clinical parameters of mother, placenta and their offspring were recorded in a standard pre-designed and pre-tested proforma. All the instruments were used with proper standard operating procedures.

\subsection{Methods of specimen collection, preparation, and assessment of placental morphometry:}

- Placentae were collected soon after separating the baby from the umbilical cord. The collected placentae were examined thoroughly and washed under running tap water, thereafter, membranes were trimmed.

- The specimens were tagged with numbers for identification, and were transported to the skill lab by placing in a $10 \%$ formalin container.

- The weight of each placenta was determined by an electronic balance and recorded accurately.

- The maternal surface area of the placenta was calculated using the formula [4]

Surface area $=\pi \mathrm{x}$ dl $\mathrm{x}$ ds $/ 4$, (where dl: largest diameter, ds: smallest diameter)

The Surface area was calculateded accurately.

- The volume of placenta was recorded using water displacement method [5].

- The thickness was measured by inserting a calibrated Knitting needle at the center of placenta and measured in centimeter, with accuracy of $0.1 \mathrm{~cm}$.

\subsection{Maternal parameters assessed were:}

Basic information of women regarding social-demographic factors; age, height, weight, and parity of mothers were recorded from in patient records. Age was classified into 4 groups; less than 20 years, 20 to 24 years, 25 to 29 years, and equal to or more than 30 years. Prepregnancy BMI was computed from first trimester weight and height measurements.BMI was grouped into 4 categories as underweight (less than 18.5), normal (18.5 - 22.9), overweight (equal to or more than 23.0) [6]. Parity was classified in 2 groups primi-para and multi-para.

Present obstetric history of pregnant women was recorded from in patient record: Vomiting was categorized into 3 groups; no vomiting, mild (morning sickness), and severe (hyperemesis gravidum). Blood pressure was categorized into 3 groups; normal-140/90 mm of Hg, either systolic or diastolic blood pressure is increased (systolic increased more than $140 \mathrm{~mm}$ of $\mathrm{Hg}$ or diastolic increased more than $90 \mathrm{~mm}$ of $\mathrm{Hg}$ ), both systolic and diastolic blood pressure increased more than 140/90 mm of Hg. Oedema was grouped into 3 classes; no oedema, mild oedema (peripheral oedema localised to toes, ankle, and lower legs), severe oedema (generalised oedema). Pallor was classified into dichotomous groups. Antepartum haemorrhage (bleeding from the genital tract after the $20^{\text {th }}$ week of pregnancy and before the onset of labour, due to placental abruption or praevia) was classified into dichotomous groups. Anaemia was classified into 4 groups; mild (Hb 10.0-10.9 $\mathrm{g} / \mathrm{dl}$ ), moderate $(\mathrm{Hb} 7.0-9.9 \mathrm{~g} / \mathrm{dl})$, severe $(\mathrm{Hb}<7.0 \mathrm{~g} / \mathrm{dl})$, normal (equal to or more than $11 \mathrm{~g} / \mathrm{dl})$ [7]. Urine test was classified into 4 groups; normal, on basis of the presence of proteins, sugar, and cells in urine.

\subsection{Parameters of newborn baby assessed were:}

- Gestational age, weight of the baby, any visible anomalies, live birth /still birth.

- The gestational age was recorded from last menstrual period (LMP) and further confirmed by Ultrasonography (USG); grouped as 28-32, 33-36, 37-40, and greater or more than 41 weeks (wk).

- Birth weight was grouped in two groups; less than 2500 and $2500 \mathrm{gm}$ and measured by using Digital baby weighing scale CS-8316(CE certified) accurately.

Statistical analysis was carried out using SPSS-16. The differences in means were tested using Analysis of Variances and comparisons of means were studied by $\mathrm{t}$-test. Differences were considered statistically significant at $\mathrm{p}$ value less than $0.05,0.01$.

\section{Results:}

The placental morphometry from 164 consecutive deliveries, birth weight and maternal factors associated with adverse pregnancy symptoms were studied.

Table 1: Basic maternal profile

\begin{tabular}{|l|c|c|}
\hline \multicolumn{1}{|c|}{ Variables } & $\mathrm{n}$ & $\mathbf{( \% )}$ \\
\hline Total & 164 & 100 \\
\hline \multicolumn{2}{|l|}{ Birth weight in gm } & \\
\hline$<2500$ & 65 & 39.6 \\
\hline$\geq 2500$ & 99 & 60.4 \\
\hline Gestation in wks(164) & \\
\hline $28-32$ & 15 & 9.3 \\
\hline $33-36$ & 20 & 12.3 \\
\hline
\end{tabular}




\begin{tabular}{|l|c|c|}
\hline $36-40$ & 122 & 74.1 \\
\hline$\geq 41$ & 7 & 4.3 \\
\hline \multicolumn{2}{|l|}{ Age groups (n=164) } \\
\hline$<20$ & 4 & 2.4 \\
\hline $20-24$ & 91 & 55.5 \\
\hline $25-29$ & 53 & 32.3 \\
\hline$\geq 30$ & 16 & 9.8 \\
\hline BMI (n=164) & 62 & 38.3 \\
\hline$<18.5$ & 65 & 40.1 \\
\hline $18.5-22.9$ & 37 & 21.6 \\
\hline$\geq 23$ & 79 & 48.8 \\
\hline Parity(164) & 85 & 51.2 \\
\hline Primi & \multicolumn{2}{|l}{} \\
\hline Multi &
\end{tabular}

Table 1, Basic maternal profile reveals that 39.6 percent of the newborn were low birth weight (less than 2500 $\mathrm{gm}$ ), whereas 21.6 percent were preterm. In age group less than 20 yrs 2.4 percent babies were born, whereas, 9.8 percent babies were born in age group 30 yrs and above. In undernourished group 38.3 percent babies were born. Primiparous women were 48.8 percent.

Table-2 : Placental morphometry by adverse pregnancy symptoms and conditions.

\begin{tabular}{|c|c|c|c|c|c|c|}
\hline \multirow{3}{*}{ Characteristics } & \multirow{3}{*}{$\mathrm{n}(\%)$} & \multicolumn{5}{|c|}{ Placental morphometry } \\
\hline & & Birth weight(gm) & Weight(gm) & Volume(ml) & $\begin{array}{c}\text { Surface area } \\
(\mathrm{sq} \mathrm{cm})\end{array}$ & $\begin{array}{l}\text { Thickness } \\
\text { (cm) }\end{array}$ \\
\hline & & Mean \pm SD & Mean \pm SD & Mean \pm SD & Mean \pm SD & Mean \pm SD \\
\hline Total & $164(100)$ & $2536.1 \pm 675.5$ & $414.7 \pm 110.5$ & $363.1 \pm 113.2$ & $223.8 \pm 54.7$ & $2.1 \pm 0.5$ \\
\hline \multicolumn{7}{|c|}{ 1.Vomiting $(n=164)$} \\
\hline Absent & 67 & $2541.2 \pm 647.8$ & $414.5 \pm 101.4$ & $364.1 \pm 104.8$ & $221.8 \pm 51.8$ & $2.1 \pm 0.4$ \\
\hline Mild & 82 & $2560.8 \pm 706.9$ & $422.0 \pm 119.9$ & $370.9 \pm 122.3$ & $229.5 \pm 55.8$ & $2.1 \pm 0.5$ \\
\hline Severe & 15 & $2379.0 \pm 642.8$ & $375.5 \pm 93.1$ & $316.7 \pm 89.7$ & $201.9 \pm 59.1$ & $2.1 \pm 0.5$ \\
\hline 2.Oedema & 164 & $2536.1 \pm 675.5$ & $414.7 \pm 110.5$ & $363.1 \pm 113.2$ & $223.8 \pm 54.7$ & $2.1 \pm 0.5$ \\
\hline Absent & 145 & $2550.8 \pm 653.4$ & $414.7 \pm 105.2$ & $364.7 \pm 105.5$ & $224.6 \pm 53.8$ & $2.1 \pm 0.5$ \\
\hline Mild & 15 & $2328.6 \pm 696.1$ & $394.8 \pm 99.5$ & $330.0 \pm 115.6$ & $215.2 \pm 57.3$ & $2.0 \pm 0.4$ \\
\hline Severe & 4 & $2782.5 \pm 1316.0$ & $488.3 \pm 277.2$ & $432.5 \pm 295.7$ & $228.5 \pm 87.0$ & $2.3 \pm 0.3$ \\
\hline \multicolumn{7}{|c|}{ 3.Blood pressure $(n=164) ; * ; p<0.05 ; * * ; p<0.01$} \\
\hline Normal & 130 & $2596.4 \pm 601.4^{*}$ & $419.9 \pm 102.5^{* *}$ & $371.2 \pm 110.2 *$ & $227.4 \pm 50.8$ & $2.1 \pm 0.4 * *$ \\
\hline Either increased & 13 & $2726.9 \pm 585.5^{*}$ & $471.8 \pm 92.0 * *$ & $399.2 \pm 85.0^{*}$ & $231.0 \pm 37.7$ & $2.1 \pm 0.3 * *$ \\
\hline Both increased & 21 & $2219.5 \pm 899.3^{*}$ & $363.7 \pm 124.1 * *$ & $308.1 \pm 114.7^{*}$ & $208.6 \pm 67.2$ & $1.8 \pm 0.5^{* *}$ \\
\hline 4.Pallor & 164 & $2536.1 \pm 675.5$ & $414.7 \pm 110.5$ & $363.1 \pm 113.2$ & $223.8 \pm 54.7$ & $2.1 \pm 0.5$ \\
\hline Absent & 146 & $2556.6 \pm 673.6$ & $417.2 \pm 109.8$ & $365.4 \pm 112.9$ & $224.7 \pm 53.5$ & $2.1 \pm 0.5$ \\
\hline Present & 18 & $2369.7 \pm 687.7$ & $394.4 \pm 117.4$ & $345.0 \pm 117.2$ & $217.2 \pm 64.6$ & $2.1 \pm 0.5$ \\
\hline $\begin{array}{l}\text { 5. Antepartum } \\
\text { haemorrhage }\end{array}$ & 164 & $2536.1 \pm 675.5$ & $414.7 \pm 110.5$ & $363.1 \pm 113.2$ & $223.8 \pm 54.7$ & $2.1 \pm 0.5$ \\
\hline Absent $^{+}$ & 162 & $2549.8 \pm 668.1$ & $415.6 \pm 110.8$ & $365.0 \pm 112.5$ & $225.1 \pm 53.7$ & $2.1 \pm 0.5$ \\
\hline Present $^{+}$ & 2 & $1422.5 \pm 109.6$ & $339.0 \pm 55.2$ & $210.0 \pm 56.6$ & $122.2 \pm 45.0$ & $1.5 \pm 0.1$ \\
\hline $\begin{array}{l}\text { 6.Premature } \\
\text { rupture of } \\
\text { membrane }\end{array}$ & 164 & $2536.1 \pm 675.5$ & $414.7 \pm 110.5$ & $363.1 \pm 113.2$ & $223.8 \pm 54.7$ & $2.1 \pm 0.5$ \\
\hline Absent & 162 & $2536.0 \pm 679.7$ & $414.0 \pm 110.9$ & $363.2 \pm 113.8$ & $224.1 \pm 54.9$ & $2.1 \pm 0.5$ \\
\hline Present & 2 & $2545.0 \pm 77.7$ & $469.5 \pm 64.3$ & $355.0 \pm 35.4$ & $202.7 \pm 30.0$ & $2.0 \pm 0.6$ \\
\hline
\end{tabular}

Note:,$+ * ; \mathrm{p}<0.05 ; * * ; \mathrm{p}<0.01$

+ ; though statistically significant subjects are only 2 , hence significance is not reliable.

Table-2, Placental morphometry by adverse pregnancy symptoms and conditions reveals that overall mean placental weight was $414.7 \mathrm{gm}$ with SD 110.5, the similar figures for volume, surface area and thickness were $363.1 \mathrm{ml}$ with SD 113.2 and $223.8 \mathrm{sq} \mathrm{cm}$ with SD 54.7 and $2.1 \mathrm{~cm}$ with SD 0.5 respectively. The placental weight, volume, surface area, and thickness of mild vomiting women (morning sickness) were higher as compared to non vomiting and severe vomiting groups.

The placental morphometry of women with mild oedema were lower as compared to non-oedematous group. The mothers with severe oedema had higher birth weight and placental morphometry with very high standard deviations, amounting to very large variations in the observations.

Women with either systolic or diastolic blood pressure increased had positive and significant relationship with placental weight, thickness $(\mathrm{p}<0.01)$ volume and birth weight $(\mathrm{p}<0.05)$. Women with increased 
systolic and diastolic blood pressure had significantly decreased placental weight, thickness $(\mathrm{p}<0.01)$ volume and birth weight $(\mathrm{p}<0.05)$. Surface area did not exhibit any significant relationship with blood pressure.

The placental morphometry of mothers with pallor were lower as compared to non-pallor mothers, but the differences were not statistically significant.

The mothers with antepartum haemorrhage were two with lower birth weight and placental morphometry, the photo of placenta (Fig-1, placenta-a) have been specified to differentiate it from normal. Inspite of only two subjects the differences in birth weight and placental morphometry were significant at $\mathrm{p}<0.05$, but the differences may not remain consistent.

The mothers who had premature rupture of membranes had more placental weight, and lesser placental volume, surface area, and thickness as compared to normal women.

Table 4: Placental morphometry by haemoglobin and urine test

\begin{tabular}{|l|c|c|c|c|c|c|}
\hline \multirow{2}{*}{ Characteristics } & \multirow{2}{*}{$\mathrm{n}(\%)$} & \multirow{2}{*}{ Birth weight } & \multicolumn{4}{|c|}{ Placental morphometry } \\
\cline { 3 - 7 } & & Mean \pm SD & Weight & Volume & Surface area & Thickness \\
\cline { 3 - 7 } & 163 & $2534.52 \pm 677.33$ & $415.01 \pm 110.80$ & $363.35 \pm 113.47$ & $223.66 \pm 54.81$ & $2.09 \pm 0.45$ \\
\hline a. Haemoglobin & 77 & $2591.17 \pm 694.88$ & $416.18 \pm 112.47$ & $366.10 \pm 116.35$ & $229.65 \pm 52.84$ & $2.00 \pm 0.40$ \\
\hline Normal & 45 & $2487.60 \pm 615.62$ & $414.56 \pm 91.65$ & $357.47 \pm 95.63$ & $215.16 \pm 52.84$ & $2.17 \pm 0.41$ \\
\hline Mild & 37 & $2536.89 \pm 690.94$ & $419.19 \pm 128.34$ & $369.19 \pm 129.64$ & $221.59 \pm 62.13$ & $2.18 \pm 0.57$ \\
\hline Moderate & 4 & $1950.00 \pm 826.64$ & $358.75 \pm 130.74$ & $322.50 \pm 114.71$ & $223.14 \pm 46.35$ & $1.88 \pm 0.48$ \\
\hline Severe & 164 & $2536.14 \pm 675.57$ & $414.7 \pm 110.5$ & $363.1 \pm 113.2$ & $223.8 \pm 54.7$ & $2.1 \pm 0.5$ \\
\hline b. Urine test & 140 & $2584.68 \pm 622.91$ & $416.2 \pm 109.7$ & $367.4 \pm 113.1$ & $225.9 \pm 53.6$ & $2.1 \pm 0.5$ \\
\hline Normal & 18 & $2253.62 \pm 882.48$ & $415.5 \pm 116.3$ & $348.8 \pm 112.9$ & $228.4 \pm 52.6$ & $2.1 \pm 0.4$ \\
\hline Protienuria & 5 & $2507.00 \pm 747.31$ & $426.4 \pm 103.0$ & $350.0 \pm 110.7$ & $188.7 \pm 61.5$ & $2.1 \pm 0.6$ \\
\hline Microscopie & 1 & $2700.00 \pm 0.0$ & $371.0 \pm 0.0$ & $290.0 \pm 0.0$ & 2.0 \\
\hline Sugar & & & & & $182.3 \pm 0.0$ \\
\hline
\end{tabular}

The severe anaemia with $\mathrm{Hb}$ less than $7 \mathrm{gm} / \mathrm{dl}$ affected both birth weight and placental morphometry; however mild and moderate anaemia did not show any impact on either.

In urine test; Protienuria did not show any significant change in placental morphometry, however the presence of proteins exhibited lower birth weight, placental weight, volume, and thickness. Acute urine infections (Microscopie) did not show any impact on birth weight and placental morphometry.

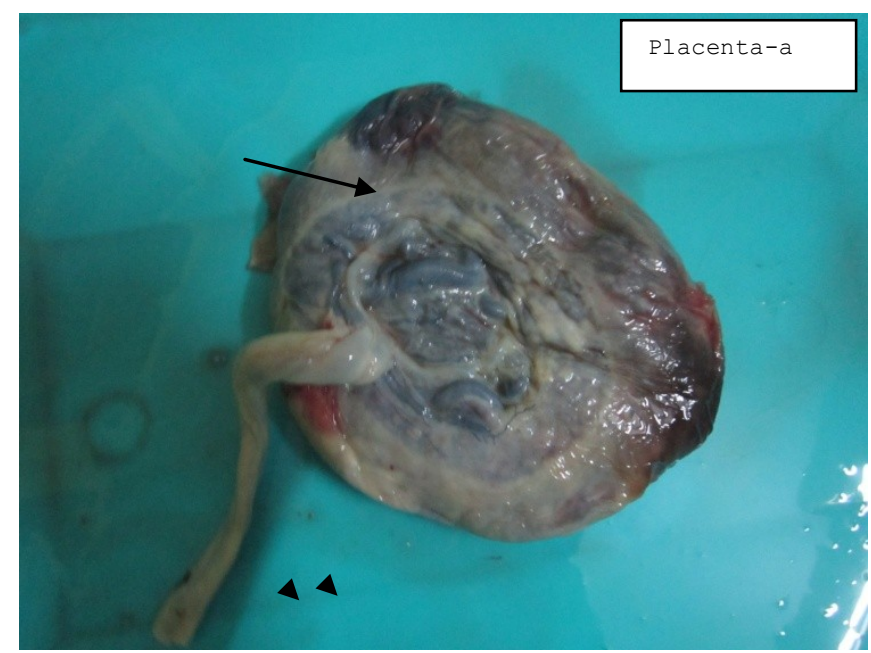

Figure-1: Abruptio placenta

Figure-1, reveals a 20 year old primi gravid, gestational age of 30 weeks, cephalic presentation, education up to $10^{\text {th }}$ grade, a house wife with a prepregnancy weight of $40 \mathrm{~kg}$, and present weight of $45 \mathrm{~kg}$ ( at $\left.30 \mathrm{wks}\right)$. She presented with pain abdomen and bleeding per vagina. She was diagnosed as a case of pre-eclampsia, along with abruptio placenta, and subsequent Intra uterine death. On examination her blood pressure was 140/96 mm of $\mathrm{Hg}$, severe oedema was present, and investigation revealed $\mathrm{Hb}$ of $9.0 \mathrm{gm} \%$, urine test showed the presence of albumin. She delivered spontaneously a fresh still born male baby weighing $1.3 \mathrm{~kg}$. Placental weight was 370 $\mathrm{gm}$, oval in shape, eccentric insertion of cord, with the diameter of 10 and $11.5 \mathrm{~cm}$ and surface area $90.36 \mathrm{sq} \mathrm{cm}$, thickness of $1.5 \mathrm{~cm}$, volume of $200 \mathrm{ml}, 9$ ill-defined cotyledons were present. It is a circum-marginate placenta, 
with decreased volume as compared to weight.

\section{Discussion}

Placental growth occurs till $37^{\text {th }}$ week, so as a result immature villi are seen even till term [8]. Placenta responds to exogenous insults and tries to adapt for varying nutritional level of mother. If this response of placenta fails to maintain foetal growth, then it results in Intra uterine growth retarded babies [9]. Therefore, variations in placental morphometry and the foetal growth are explained by the inutero environment. Therefore as expressed in the results adverse pregnancy symptoms and conditions like vomiting, oedema, pallor, antepartum hemorrhage, premature rupture of membranes, and investigations influenced the placental morphometry and birth weight in unique pattern.

Huxley reported that lower energy intakes during early pregnancy i.e due to nausea and vomiting are associated with increased placental growth, the morning sickness is due to secretion of hCG and thyroxine hormones. In turn there is reduction of maternal energy intake this leads to decreased level of anabolic hormones. Nausea and vomiting by suppressing the maternal tissue synthesis and by nutrient partitioning, facilitates the placental growth. There is an association between prepregnancy body mass index (BMI) and morning sickness, lower BMI group mothers experience less symptoms of morning sickness as compared to normal BMI group mothers. [10]. Experiments on sheep have proved that high nutrient intakes in early pregnancy may lead to reduced placental growth, resulting in decreased placental and fetal growth [11]. These results correlated with the present study the mothers with mild vomiting and nausea had increased placental weight, volume, surface area and thickness as compared to non vomiting and, severe vomiting mothers.

In the current study birth weight and placental morphometry of women with mild oedema were lower as compared to non-oedematous. There is literature paucity regarding the influence of oedema alone on placental morphometry, but surplus studies are there assessing the effect of pre-eclampsia, a triad of oedema, high blood pressure $(>140 / 90 \mathrm{~mm} \mathrm{Hg})$ and protienuria on placental morphometry. Many of the authors have reported significantly lower placental weight, volume, surface area and intra uterine growth retarded babies in pre-eclampsia $[12,13,14]$. Therefore, all these signs of pregnancy induced hypertensive disorders affect the placental morphometry by increasing the cytotrophoblastic cellular proliferation, and syncytial knot formation in villi of the placenta. This placental pathology leads to adverse perinatal outcome. In the present study women with severe oedema had higher birth weight and placental morphometry with very high standard deviations amounting to very large variations in the observations, this may be due to malnutrition, protienuria or severe anemia.

A study by Emery reported that in mild and moderate anaemia of the mother the cord blood iron levels were normal [15]. As the foetus is parasite residing in mother, in case of mild and moderate anaemia fetus inutero traps iron irrespective of maternal haemoglobin levels and gets affected only in severe anaemia by lowering the birth weight and placental morphometry. The present study correlates with above results, mild and moderate maternal anaemia did not have any impact on birth weight and placental morphometry. However, only severe anaemia had lower birth weight and placental morphometry as compared to mild and moderate anaemia In contrast to these studies one of the author has commented that severe maternal anaemia might be associated with higher placental weight [16].

Many studies have reported that placental abruption was associated with maternal anaemia, gestational hypertension, preterm and low birth weight babies, with high still birth rate. Therefore, abruptio placenta is associated with adverse maternal and fetal outcomes $[17,18]$. This aspect correlated with the present study, the abruptio placenta ( Fig-1 placenta- $a$ ) was associated with pre-eclampsia, antepartum haemorrhage, Intra uterine growth retarded, fresh still born, preterm baby. Placenta was from primi-parous women associated with moderate anaemia.

\section{Conclusion:}

Birth weight and placental morphometry increased with mild vomiting (morning sickness). Blood pressure with either systolic or diastolic increase had positive and significant relationship with placental weight, thickness $(\mathrm{p}<0.01)$ volume and birth weight $(\mathrm{p}<0.05)$. Women with increased systolic and diastolic blood pressure had significantly decreased placental weight, thickness $(\mathrm{p}<0.01)$ volume and birth weight $(\mathrm{p}<0.05)$. Surface area did not exhibit any significant relationship with blood pressure. Severe vomiting, oedema, anaemia, protienuria, exhibited consistent variation in birth weight and placental morphometry but, results were not statistically significant. Pregnant women with these risk factors mandate more vigilant monitoring of Ultrasonography to assess the growth trajectory of placenta and fetus.

\section{Recommendations:}

The results of the study can be used in maternal care during pregnancy. However, the results may need revalidation in other settings. The findings of severe oedema, anaemia, antepartum haemorrhage, premature 
rupture of membranes and protienuria need further study with larger number of subjects.

\section{References:}

[1]. Yetter JF. Examination of the Placenta. American Academy of Family Physicians, 57(5), 1998, 1045-1054.

[2]. Naeye RL. Do placental weights have clinical significance? Hum Pathol, 18, 1987, 387-91. Cited Manop J, Ounjai KA, Alan G. Placental weight and its ratio to birth weight in normal pregnancy at Songkhlanagarind Hospital. J Med Assoc Thai, 89(2), 2006, $130-137$.

[3]. Barker DJ, Bull AR, Osmond C, Simmonds SJ. Fetal and placental size and risk of hypertension in adult life. BMJ, 301,1990, 25962.

[4]. Baptiste KR, Salafia CM, Nicholson WK, Duggan A, Wang NY, Brancati FL. Maternal risk factors for abnormal placental growth: The national collaborative perinatal project. BMC Pregnancy Childbirth, 8, 2008, 44.

[5]. Scherle WF, A simple method for volumetry of organ in quantitative stereology. Microskopie., 26,1970, 57-60

[6]. Cited from :http://www.igovernment.in/site/India-reworks-obesity-guidelines-BMI-lowered/

[7]. Indian Council of Medical Research. Evaluation of the National Nutritional Anaemia Prophylaxis Programme. Task Force Study. New Delhi: ICMR, 1989.

[8]. Fox H, Sebire N, Pathology of placenta. 3rd ed (Houston M, McCormick H, eds.) Philadelphia: Elsevier; 2007.

[9]. Cross JC. The genetics of pre-eclampsia: a feto-placental or maternal problems? Cli genetics, 64, 2000, 96-103.

[10]. Huxley RR.. Nausea and Vomiting in early pregnancy: Its role in placenta development. Obstet Gynecol , 95 (5), $2000,779-782$.

[11]. Robinson J, Chidzanja S, Kind K, Lok F, Owens P, Owens J. Placental control of fetal growth. Reprod Fertil Dev, 7, 1995, 333-344.

[12]. Virupaxi RD, Potturi BR, Shirol VS, Desai SP, Hukkeri VB. Morphology of placenta and its relation with small for date babies in 950 Live births. Recent Research in Science and technology, 3(2), 2011, 123-126.

[13]. Udania A, Jain ML. Morphological Study of Placenta in pregnancy induced hypertension with its clinical relevance Anat Soc India; 50(1), 2001, $24-27$.

[14]. Rath G, Garg K, Sood M.. Insertion of umbilical cord on the placenta in the hypertension mother. J. Anat. Soc. India, 49(2), 2000, $149-152$.

[15]. Emery D, Bary D. Comparision of Maori and non Maori maternal and fetal iron parameters. The New Zealand Medical Journal, 117, 2004, 1195.

[16]. Beischer NA, Sivasamboo R, Vohra S, Silpisornkosal S, Reid S . Placental hypertrophy in severe maternal anaemia. Journal of Obstetrics and Gynaecology of the British Commonwealth, 77, 1970, 398-409.

[17]. Seema B, Saima G, Mohammad AP, Sajida Yousfani .. Risk factors and clinical outcome of placental abruption : a retrospective analysis. JPMA, 59, 2009, 672-674.

[18]. Incerpi MH. Still birth evaluation, what tests are needed ? Am J Obstet Gynecol, 178, 1998, 1121-1128. 